\title{
Microstructure and Gas-Sensing Property of Titania-Added $\mathrm{ZnSnO}_{3}$
}

\author{
Wen Zeng ${ }^{1,2}$, Tianmo Liu ${ }^{1, *}$ and Zhongchang Wang ${ }^{2, *}$ \\ ${ }^{1}$ College of Materials Science and Engineering, Chongqing University, Chongqing 400044, P. R. China \\ ${ }^{2}$ WPI Research Center, Advanced Institute for Materials Research, Tohoku University, Sendai 980-8577, Japan
}

\begin{abstract}
We report the microstructure and gas-sensing property of $\mathrm{TiO}_{2}$-loaded $\mathrm{ZnSnO}_{3}$ prepared by three different addition methods. We find that the loading of $\mathrm{TiO}_{2}$ enables a significant improvement of sensor response and selectivity to ethanol and that the wet process, which is defined as the introduction of $\mathrm{TiO}_{2}$ gel to $\mathrm{ZnSnO}_{3}$ precipitants, is most efficient to enhance the gas-sensing behaviors. Microscopically, surface characterizations suggest that the improved sensing properties for the $\mathrm{TiO}_{2}$-loaded $\mathrm{ZnSnO}_{3}$ can be attributed qualitatively to its large specific surface area and porous morphology. A gas adsorption model based on surface physics is proposed to discuss further the mechanism behind the sensing property enhancement. This study may open up an avenue for effectively tuning gas-sensing character of $\mathrm{ZnSnO}_{3}$, which is important for modifying functionality of other sensing materials. [doi:10.2320/matertrans.M2010017]
\end{abstract}

(Received January 19, 2010; Accepted April 26, 2010; Published June 16, 2010)

Keywords: $\mathrm{ZnSnO}_{3}$-based gas sensor, $\mathrm{TiO}_{2}$ additive, microstructure, sensing property

\section{Introduction}

One of the most active fields in sensor research is the exploration of new materials that enable enhanced gassensing functionalities. ${ }^{1-10)}$ As one of the complex $\mathrm{ABO}_{3}$ compounds, zinc stannate $\left(\mathrm{ZnSnO}_{3}\right)$ has attracted a widespread attention lately, largely because in comparison to binary oxides, it is easier to form defects inside it or on its surface, which are important for detecting gases. ${ }^{11-13)}$ Moreover, its gas-sensing character can be improved significantly via the addition of not only noble metals, for example, Pd and $\mathrm{Pt}$, but also more importantly, metal oxide like $\mathrm{SnO}_{2}, \mathrm{ZnO}$, and $\mathrm{TiO}_{2}{ }^{14-17)}$ Although it has been known that these cheap oxide additives are capable of altering or improving the gassensing functionality of $\mathrm{ZnSnO}_{3}$, little is known about how the loading methods affect the properties, which if well understood, could provide a guideline for mass production on an industrial level. In general, a detailed knowledge on such effect requires a bridging study of microstructures of $\mathrm{ZnSnO}_{3}$-based sensors fabricated by different loading ways to the gas-sensing properties, and this has so far been lacking. In this paper, we address this issue by preparing $\mathrm{TiO}_{2}$-loaded $\mathrm{ZnSnO}_{3}$ sensing materials through three different approaches, aimed at developing a reliable and practical fabrication process for $\mathrm{ZnSnO}_{3}$-based sensors. In addition to observing the microstructures, the goal of this study is to compare the gas-sensing behaviors for the $\mathrm{ZnSnO}_{3}$-based materials fabricated by the different loading methods.

\section{Experimental}

The $\mathrm{ZnSnO}_{3}$ powders were prepared using the coprecipitation method. First, the $\mathrm{ZnSO}_{4} \cdot 7 \mathrm{H}_{2} \mathrm{O}$ (Aldrich, 99.9\%) and $\mathrm{SnCl}_{4} \cdot 5 \mathrm{H}_{2} \mathrm{O}$ (Aldrich, $99.9 \%$ ) were used as starting materials and $\mathrm{NH}_{3} \cdot \mathrm{H}_{2} \mathrm{O}$ was applied as a coprecipitant. These materials were then dissolved in distilled water and the $\mathrm{NH}_{3} \cdot \mathrm{H}_{2} \mathrm{O}$ solution was subsequently dropped in so as to adjust $\mathrm{pH}$ of the mixed solution to about 7 . The white precipitates were

*Corresponding author, E-mail: tmliu@cqu.edu.cn; zcwang@wpi-aimr. tohoku.ac.jp generated immediately after the introduction of $\mathrm{NH}_{3} \cdot \mathrm{H}_{2} \mathrm{O}$. These precipitates were finally filtered, washed, and dried at $393 \mathrm{~K}$ to produce $\mathrm{ZnSnO}_{3}$ precursors, which were used in part to obtain powder (named as sample TZ0) by calcination at $873 \mathrm{~K}$ for $4 \mathrm{~h}$. Similarly, the $\mathrm{TiO}_{2}$ colloidal solution was prepared by first mixing $10 \mathrm{~mL}$ of tetra butyl titanium (Wako Pure Chemical, 95\%) with isopropyl alcohol (4 mL). Next, this mixture was added gradually into deionized water of $150 \mathrm{~mL}$ under intensive stirring for several hours until the sol was formed. The sol was finally transferred into a well sealed autoclave vessel containing $0.5 \mathrm{M}$ teramethy-ammonium hydroxide solution and heated at $393 \mathrm{~K}$ for $6 \mathrm{~h}$. The fine powder of $\mathrm{TiO}_{2}$ was prepared through desiccating the colloidal precipitate at $353 \mathrm{~K}$, followed by amply mechanical milling.

We applied three preparation methods to introduce the $\mathrm{TiO}_{2}$ into the $\mathrm{ZnSnO}_{3}$ under a concentration of $10 \%$ (in mol): (i) mixing homogenously the commercially available $\mathrm{TiO}_{2}$ powder with the prepared TZ0 powder (named as TZ1), (ii) mixing evenly the home-made nanoscale $\mathrm{TiO}_{2}$ powder with the TZ0 powder (named as TZ2), and (iii) adding the $\mathrm{TiO}_{2}$ gel to the $\mathrm{ZnSnO}_{3}$ precipitants under mechanical stirring and drying the solution (named as TZ3). It is worthy of note that the first two methods belong to the dry process, which is generally defined as the introduction of solid additive to the solid host powder under milling. On the other hand, the last method is classified into a wet process because the addition of a gel to the other is taken in liquid or colloid. The gas sensors were fabricated by coating the paste of powder onto the $\mathrm{Al}_{2} \mathrm{O}_{3}$ tube (with a diameter of $1.2 \mathrm{~mm}$ ), which has two $\mathrm{Au}$ electrode wires that are separated at each end of the tube by $6 \mathrm{~mm}$. The coated ceramic tubes were finally sintered at $673 \mathrm{~K}$ for $2 \mathrm{~h}$, forming a covered sensing film with thickness of about $30 \mu \mathrm{m}$.

Microstructure analyses of the prepared powders were performed using the X-ray diffraction (XRD). A Shimadzu XD-5A diffractometry with $\mathrm{Cu} K \alpha$ radiation operated at $30 \mathrm{kV}$ and $100 \mathrm{~mA}$ was applied. The surface morphologies of both the pristine and additive-loaded samples after sintering were observed using a JEOL JSM-5510 scanning electron microscope (SEM). Gas-sensing properties were measured 
using a static measurement system that was controlled automatically by computer. During the measurement, the sensor substrate was first powered at $373 \mathrm{~K}$ for $120 \mathrm{~h}$ in air and then operated at $303 \mathrm{~K}$ with a relative humidity of $40 \%$. The sensor response was defined as a ratio of resistance in air $\left(R_{a}\right)$ to that in detected gas $\left(R_{g}\right)$.

\section{Results and Discussion}

\subsection{Microstructure characterization}

To determine chemical composition of the prepared powders, we first performed the XRD analysis, as shown in Fig. 1, where textural orientations of the detected matters are given as well for easy reference. As expected from the aforementioned preparation process, one can see in Fig. 1(a) only peaks of $\mathrm{ZnSnO}_{3}$ in the sample before loading of the $\mathrm{TiO}_{2}$ additive. Further, we note that the sample shows a number of different textural orientations, indicating of polycrystalline character. On the other hand, the XRD spectrum alters after introducing the additive (Figs. 1(b)1(d)), as new $\mathrm{TiO}_{2}$ peaks emerge, which suggests that we have successfully added $\mathrm{TiO}_{2}$ into the $\mathrm{ZnSnO}_{3}$. One feature in common is that the loaded samples remain polycrystalline, with the highest peak intensity for the (101) texture of $\mathrm{ZnSnO}_{3}$. However, we have not yet detected unambiguously any other compounds in the loaded samples, for example, $\mathrm{ZnTiO}_{3}$ or $\mathrm{Zn}_{2} \mathrm{SnO}_{3}$, thereby suggesting that the applied loading methods might affect insignificantly the chemical composition of $\mathrm{ZnSnO}_{3}$. Furthermore, this indicates (i) that the intensities of these compounds, if present, are so low that may be overlapped by the strong peaks of $\mathrm{ZnSnO}_{3}$, and (ii) that there may be no such newly formed compounds at all in the loaded samples.

Figure 2 shows SEM micrographs for the surfaces of the sensors fabricated from both pristine and $\mathrm{TiO}_{2}$-added samples. From this figure, we note that the surface morphologies vary noticeably, as the surface of sample TZ3 is comparably looser with a larger amount of pores than the rest of samples. Furthermore, these pores are unevenly distributed on the TZ31 surface with size ranging from 2 to $10 \mu \mathrm{m}$. Since it is known that the pores may offer tunnels to transit the gas into the $\mathrm{ZnSnO}_{3}$, the TZ3 samples could enhance the adsorption of tested gas and hence induce even more significant change in electric conductivity (i.e., sensor

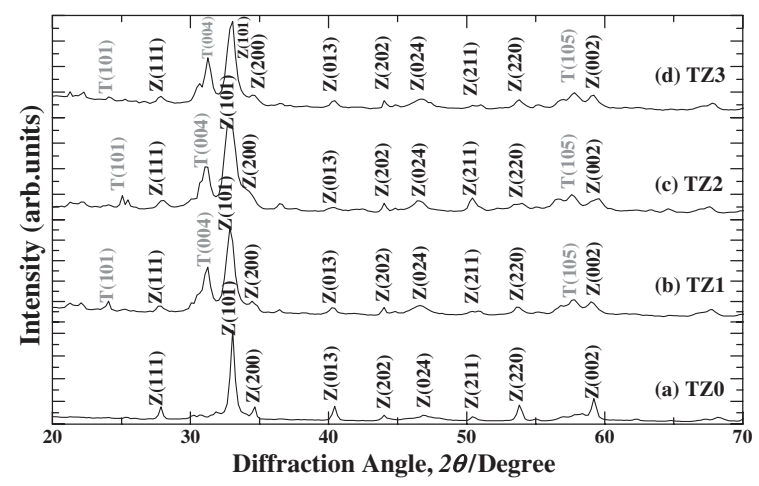

Fig. 1 X-ray diffraction patterns of pristine $\mathrm{ZnSnO}_{3}$ powder and the powders prepared via the three different loading methods.
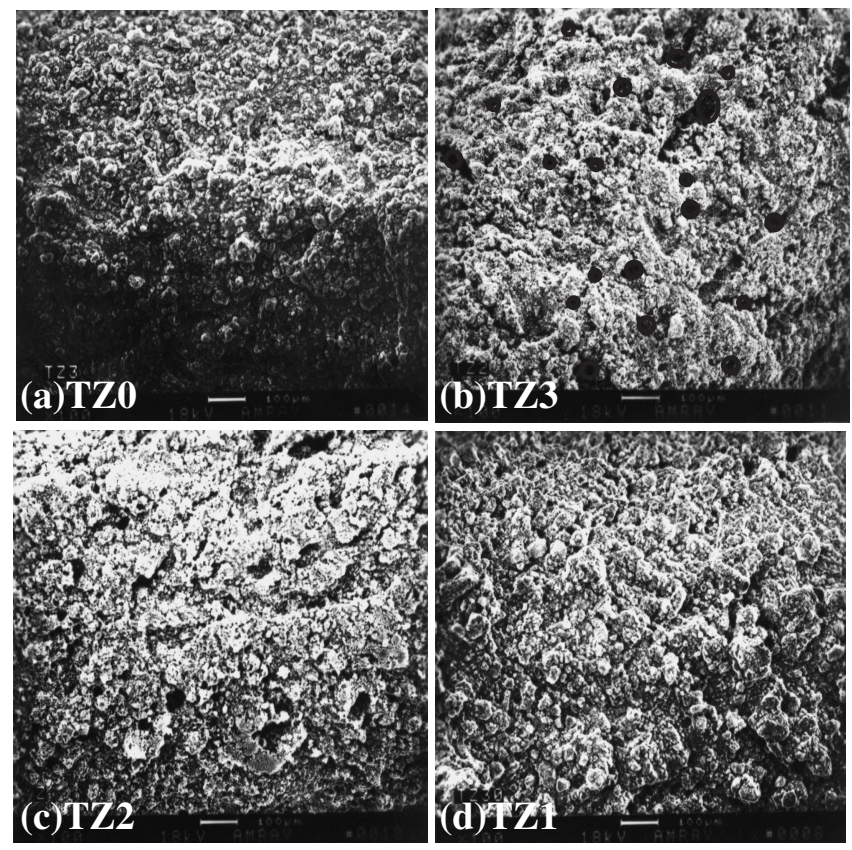

Fig. 2 SEM micrographs of surfaces of the sensors fabricated from samples (a) TZ0, (b) TZ3, (c) TZ2, and (d) TZ1.

response), as will be presented later. The other factor that affects the sensing mechanism qualitatively is the specific surface area, which is measured using the BET (Brunauer, Emmett, and Teller) method. The obtained specific surface area for the sample TZ3 is $34.9 \mathrm{~m}^{2} / \mathrm{g}$, much larger than those of the samples TZ2, TZ1, and TZ0 having values of 22.8 , 22.5 , and $12.3 \mathrm{~m}^{2} / \mathrm{g}$, respectively, which indicates that the TZ31 surface has the smallest particle size. Importantly, this largest specific surface area may facilitate the interaction between the semiconductor surface and the gas molecule, which triggers even more substantial output in electric signal. This, together with the large amount of surface pores, suggests qualitatively that the TZ3 may exhibit an optimal sensing behavior.

\subsection{Gas-sensing properties}

To testify this conjecture, we first measured the response of the sensors fabricated using both the pristine and $\mathrm{TiO}_{2}-$ loaded $\mathrm{ZnSnO}_{3}$ to several species of gases, for example, $\mathrm{C}_{2} \mathrm{H}_{5} \mathrm{OH}, \mathrm{CO}_{2}, \mathrm{C}_{2} \mathrm{H}_{2}, \mathrm{H}_{2}$, LPG, and $\mathrm{NH}_{3}$ under a fixed concentration of $800 \mathrm{ppm}$. We have mainly considered these gases because (i) most, if not all, of them are reductive or harmful gases, and (ii) there are many previous reports on the sensing behaviors of these gases so that we can have a better comparison of our results with the published data. However, we have not yet selected the aldehyde, a disturbing gas that is similar to ethanol in both structure and property, owning to its instability in air, i.e., easy decomposition to ethanol even at room temperature. In addition, further investigation of other candidate gases such as water vapor and acetone is still under way. From Fig. 3, one can see first that all samples show a higher sensor response to ethanol gas in comparison to other investigated gases, meaning exclusive selectivity to ethanol for the $\mathrm{ZnSnO}_{3}$-based sensors. Of all the samples, the TZ3 shows the highest sensor response with a value of 


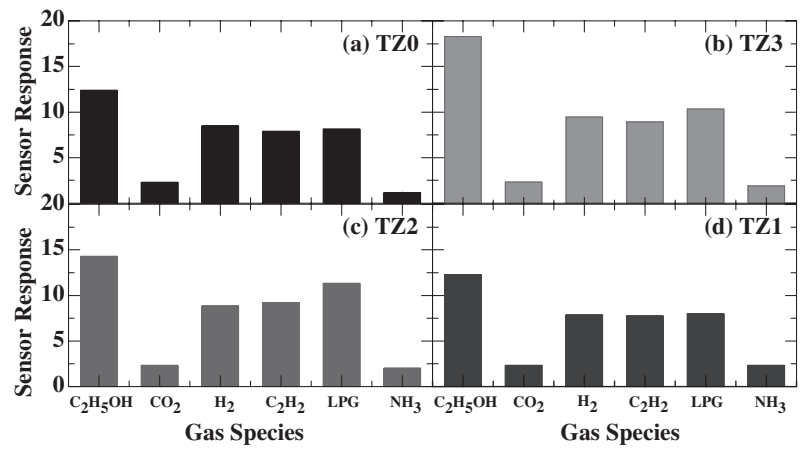

Fig. 3 Response for the sensors fabricated using the samples (a) TZ0, (b) TZ3, (c) TZ2, and (d) TZ1. The concentration is fixed to be $800 \mathrm{ppm}$ for all target gases.

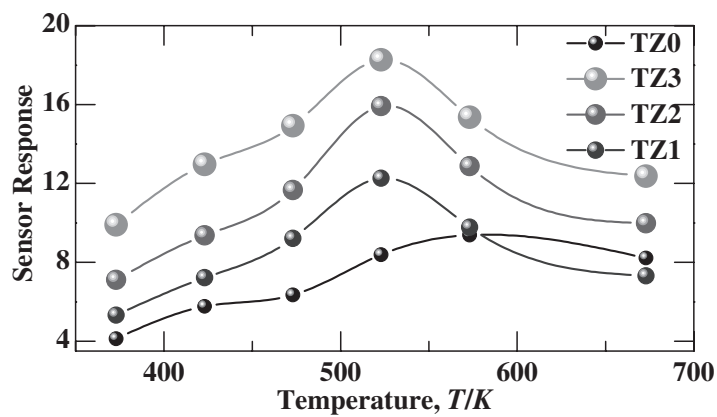

Fig. 4 Sensor response as a function of operating temperature for the sensors manufactured using both the pristine and $\mathrm{TiO}_{2}$-loaded $\mathrm{ZnSnO}_{3}$. The ethanol concentration is fixed at $800 \mathrm{ppm}$ for all samples.

approximately 18 (Fig. 3(b)), which suggests that the $\mathrm{TiO}_{2}$ additive plays an important role in improving the sensing character of $\mathrm{ZnSnO}_{3}$ and that the use of wet process facilitates this improvement.

In light of the selectivity, we then examined the sensor response to the ethanol gas under a variety of operating temperatures, as shown in Fig. 4. From this figure, we note that the sensor response increases at an initial stage but decreases afterwards with the continuing rise of temperature, thereby passing through a zenith at $523 \mathrm{~K}$. This can be explained qualitatively from a dynamic balance between initial fast adsorption of ethanol molecule and the further acceleration of desorption, as the temperature maintains rising. ${ }^{17)}$ Moreover, this can also be understood by considering the other possibility: the reaction rate between the ethanol and the sensing material increases as temperatures increases to the optimal value, and further decrease of sensor response after the optimum can be ascribed to the reduced gas concentration due to the combustion of the tested gas. ${ }^{18)}$ The maxima of sensor response for the samples TZ3, TZ2, TZ1, and TZ0 are estimated to be $18,15,12$, and 8 , respectively, which reveals again the critical role of $\mathrm{TiO}_{2}$ additive and wet process in enhancing the gas sensing of $\mathrm{ZnSnO}_{3}$.

Figure 5 shows the dependence of sensor response as a function of concentration of ethanol gas for the sensors fabricated using the pristine and $\mathrm{TiO}_{2}$-loaded $\mathrm{ZnSnO}_{3}$. We find again that of all the samples, the TZ3 always shows the largest sensor response in the measured concentrations ranging from 200 to $1000 \mathrm{ppm}$, although it is well known

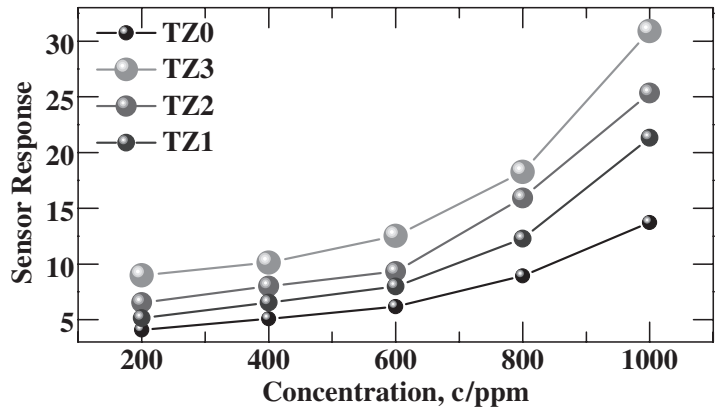

Fig. 5 Correlation between responses of the sensors fabricated using the pristine and $\mathrm{TiO}_{2}$-loaded $\mathrm{ZnSnO}_{3}$, and the concentration of ethanol gas. The measured temperature is selected to be $523 \mathrm{~K}$.

that the response may be affected by the concentration of examined gas. Further, we notice that independent of the samples the sensor response increases in a nonlinear manner with the rise of gas concentration, which can be explained from the gas-diffusion theory. ${ }^{18)}$ From this theory, the response of a oxide-based sensor $(S)$ can be empirically expressed by $S=a[C]^{n}+b$, where $a$ and $b$ are constants and $[C]$ is the concentration of the target gas. In general, the index $n$ has a value ranging from 0.5 to 1.0 , depending on the charge of surface species, stoichiometry of the elementary reactions on surface, and the variable gas concentration inside the film. In addition, the observed nonlinearity may also caused by the possible cracks in sensing film. ${ }^{19)}$

\subsection{Gas-sensing mechanism}

As aforementioned, the unevenly distributed pores may provide tunnels to transit the target gas into the $\mathrm{ZnSnO}_{3}$ interior, which can therefore enhance the adsorption of the gas. Since it is well known that the $\mathrm{ZnSnO}_{3}$ is an $n$-type semiconductor $^{20)}$ and its sensing character is governed by the change of surface resistance, the species and amount of chemisorbed oxygen on surface are critical for the variation in resistance, i.e., sensor response. As the sensor is first aged in air, oxygen can be absorbed on its surface and act as a trap for the conduction band electrons of $\mathrm{ZnSnO}_{3}$ due to their strong electronegativity. The absorbed oxygen could cause a depletion layer and band bending on the surface, which consequently increases the energy barrier, namely, the resistance of the sensing material $\mathrm{ZnSnO}_{3}$. As the reductive gas, for example, $\mathrm{C}_{2} \mathrm{H}_{5} \mathrm{OH}$, is introduced, chemical reactions take place between the $\mathrm{C}_{2} \mathrm{H}_{5} \mathrm{OH}$ and the ionized oxygen $\mathrm{O}^{2-}$, which gives out electrons back to the $\mathrm{ZnSnO}_{3}$ surface. The possible reactions are summarized by the following equations: ${ }^{21-23)}$

$$
\begin{gathered}
\mathrm{C}_{2} \mathrm{H}_{5} \mathrm{OH}(\text { gas })+\mathrm{O}^{2-}(\text { ads }) \rightarrow \mathrm{C}_{2} \mathrm{H}_{5} \mathrm{O}^{-}(\text {gas })+\mathrm{OH}^{-}(\mathrm{ads}), \\
\mathrm{C}_{2} \mathrm{H}_{5} \mathrm{O}^{-}(\text {gas }) \rightarrow\left(\mathrm{C}_{2} \mathrm{H}_{5}\right)_{2} \mathrm{O}(\text { ads })+\mathrm{O}^{-}(\text {ads })+\mathrm{e}^{-}, \\
2 \mathrm{C}_{2} \mathrm{H}_{5} \mathrm{OH}(\text { gas })+\mathrm{O}^{2-}(\text { ads }) \rightarrow 2 \mathrm{C}_{2} \mathrm{H}_{4} \mathrm{O}^{-}(\text {ads })+2 \mathrm{H}_{2} \mathrm{O}, \\
\mathrm{C}_{2} \mathrm{H}_{4} \mathrm{O}^{-}(\text {ads }) \rightarrow \mathrm{CH}_{3} \mathrm{CHO}(\text { ads })+\mathrm{e}^{-}, \\
\mathrm{CH}_{3} \mathrm{CHO}(\text { ads })+5 \mathrm{O}^{2-}(\text { ads }) \rightarrow 4 \mathrm{CO}_{2}+4 \mathrm{H}_{2} \mathrm{O}+10 \mathrm{e}^{-} .
\end{gathered}
$$

In general, there are two types of reactions occurring simultaneously on the oxide surface: (i) the target gas molecules react with the pre-absorbed oxygen, and (ii) the target gas molecules react directly with the surface atoms of 
oxide. Whatever the reaction type, the electrons that are produced from these reactions would decrease the resistance significantly, which result in drastic increase of output voltage. Likely, the pores appeared on the surface act as channels to facilitate the adsorption of $\mathrm{O}_{2}$ and $\mathrm{C}_{2} \mathrm{H}_{5} \mathrm{OH}$ molecules, which facilitates further chemical reactions. This, together with the large number of observed pores on TZ31 surface, explains its most drastic change of resistance after the exposure to ethanol. Since the sensor response relies directly on the variation in electric conductivity, the sample TZ3 exhibits the highest response to ethanol compared to any other samples. Moreover, the results presented in this work demonstrate that not only the species of additives but also the loading method are important in improving the sensing behaviors of $\mathrm{ZnSnO}_{3}$. Further clarification on its sensing mechanism requires in-depth investigations experimentally and theoretically.

\section{Conclusions}

We have applied three preparation ways to introduce $\mathrm{TiO}_{2}$ to $\mathrm{ZnSnO}_{3}$ sensing material and compared the gas-sensing properties of the loaded samples, aimed at revealing the fundamental effect of loading method on sensing character. We find that the loading of $\mathrm{TiO}_{2}$ can indeed improve the gassensing properties of $\mathrm{ZnSnO}_{3}$ and the wet loading process enables further enhancement of response and selectivity of the $\mathrm{ZnSnO}_{3}$-based sensor. Using several surface analytic techniques, we have attributed qualitatively the property improvement for the $\mathrm{TiO}_{2}$-loaded $\mathrm{ZnSnO}_{3}$ prepared by the wet process to its largest specific surface area and loosest surface morphology. These findings may be relevant for the technological improvement of sensing characteristics in $\mathrm{ZnSnO}_{3}$-based sensors, and this paper may present a new likely way to modify functionality of other sensing materials.

\section{Acknowledgements}

This work was supported in part by a Grant-in-Aid for Young Scientists (B) under Grant No. 22760500, and by the IKETANI science and technology foundation (Grant
No. 0221047-A). W. Z acknowledges the Chinese Scholarship Council (CSC) project for scholarship support (LJC20093012).

\section{REFERENCES}

1) Y. Yamada, K. Yamashita, Y. Masuoka and Y. Seno: Sens. Actuators B 77 (2001) 12-15.

2) D. H. Kim, J. Y. Yoon, H. C. Park and K. H. Kim: Sens. Actuators B 62 (2001) 61-66.

3) I. T. Weber, R. Andrade, E. R. Leite and E. Longo: Sens. Actuators B 72 (2001) 180-183.

4) A. Cirera, A. Dieguez, R. Diaz, A. Cornet and J. R. Morante: Sens. Actuators B 58 (1999) 360-364.

5) R. Srivastava, R. Dwivedi and S. K. Srivastava: Sens. Actuators B 50 (1998) 175-180.

6) Z. Deng, X. Fang, D. Li, S. Zhou, R. Tao, Wei. Dong, T. Wang, G. Meng and X. Zhu: J. Alloy. Compd. 484 (2009) 619-621.

7) N. Khakpash, A. Simchi and P. Kohi: J. Alloy. Compd. 470 (2009) 289-293.

8) C. R. Michel, A. H. Martinez, F. Huerta-Villalpando and J. P. MoranLazaro: J. Alloy. Compd. 484 (2009) 605-611.

9) M. Kugishima, K. Shimanoe and N. Yamazoe: Sens. Actuators B 118 (2006) 171-176.

10) Y. H. Choi, M. Yang and S. H. Hong: Sens. Actuators B 134 (2008) 117-121.

11) Z. Wang, T. Liu and L. Yu: J. Chin. Ceram. Soc. 32 (2004) 1555-1559.

12) C. Wang, X. Wang, J. Zhao, B. Mai, G. Sheng, P. Peng and J. Fu: J. Mater. Sci. 37 (2002) 2989-2996.

13) B. Geng, C. Fang, F. Zhan and N. Yu: Small 4 (2008) 1337-1343.

14) J. Q. Xu, X. H. Jia, X. D. Lou and J. N. Shen: Solid State Electronics 50 (2006) 504-507.

15) T. H. Zhang, Y. S. Shen and R. F. Zhang: Mater. Lett. 23 (1995) 69-71.

16) X. H. Wu, Y. D. Wang, H. L. Liu, Y. F. Li and Z. L. Zhou: Mater. Lett. 56 (2002) 732-736.

17) J. Q. Xu, X. H. Jia, X. D. Lou, G. X. Xi, J. J. Han and Q. H. Gao: Sens. Actuators B 120 (2007) 694-699.

18) G. Sakai, N. Matsunaga, K. Shimanoe and N. Yamazoe: Sens. Actuators B 80 (2001) 125-131.

19) S. Gong, J. Liu, J. Xia, L. Quan, H. Liu and D. Zhou: Mater. Sci. Eng. B 164 (2009) 85-90.

20) D. E. Williams: Sens. Actuators B 57 (1999) 345-349.

21) L. Nanis and G. Advani: Int. J. Electron. 52 (1982) 345-349.

22) T. S. Rantala, V. Lantto and T. T. Rantala: Sens. Actuators B 13 (1993) 234-237.

23) X. H. Wu, Y. D. Wang, Y. F. Li and Z. L. Zhou: Mater. Chem. Phys. 77 (2002) 588-593. 